Obwohl Arbeiten über die Entwickelung der Nebenniere bei fast allen Klassen der Vertebraten vorliegen, herrscht doch in Beziehung auf eine ganze Reihe von wichtigen Details noch völlige Uneinigkeit, die soweit geht, dass fast jede neue Untersuchung Thatsachen zu Tage fördert, die mit früher gemachten Beobachtungen nur selten und zum kleinsten Teil zusammenstimmen. Zu diesen Fragen gehört zunächst die, aus welchem Blastem die Nebenniere stamme; ferner, ob Rinde und Mark ein und dasselbe Entwickelungsblastem besitzen, also entwickelungsgeschichtlich identische Bildungen seien, oder der eine Nebennierenbestandteil, die Rinde, epithelialer, der andere, das Mark, nervöser Natur sei. Im engsten Zusammenhang mit dieser Frage ist die Frage, ob die Nebenniere der Säuger den Supra-, resp. Interrenalkörpern der Selachier homolog sei; ferner ob die Nebenniere der Säugetiere rein drüsiger oder nervöser Natur sei, ob gemischt; diese Fragen hängen selbstverständlich mit der Histologie des Organes aufs innigste zusammen.

Wenn ich daher die Zahl der Arbeiten über die Nebenniere um eine weitere vermehre, so geschah es von dem Gedanken aus, dass einerseits gerade die menscbliche Nebenniere weniger untersucht wurde, als die der Tiere und dann in jüngster Zeit durch die Arbeiten Kohns, Aichels und Zuckerkandls speziell die Frage nach der Abstammung des Markes in ein neues Licht gerückt wurde. Ich meine damit die Stellung der 
Marksubstanz zu jenen Organen, welche als charakteristischen Bestandteil die chromaffinen Zellen enthalten, welche Organe Kohn als „Paraganglien" bezeichnet hat, als er den Nachweis führte, dass die Carotisdrüse zum grössten Teil aus jenen Elementen bestehe. Er supponiert auch für die Nebenniere solche Zellen als eigentlichen Marksubstanzbestandteil. Im schärfsten Gegensatz zu diesen Untersuchungen, auch zu jenen, die ich beim Schweine durchführte, steht die Behauptung Aichels, welcher für beide Substanzen ein und dasselbe Stroma, die Querkanälchen der Urniere, in Anspruch nimmt. Ein besonderes Interesse gewann die Untersuchung der Entwickelung der Marksubstanz in allerjüngster Zeit durch die Entdeckung Zuckerkandls, dass sich im Retroperitonaealraum des Menschen aus dem Sympathicus und unabhängig von der Marksubstanz Organe entwickeln (der mächtigste Anteil zu beiden Seiten der Art. mesent. inf.), die ihrem Aufbaue nach ,chromaffine Organe reinster Art" darstellen. Es lag nun nahe, speziell die Beziehung und Entwickelung dieser Organe zum „Paraganglion suprarenale" festzustellen, um so einerseits über die Natur der Marksubstanz völlig Klarheit zu gewinnen und andererseits auch der Entwickelung der chromaffinen Zelle überhaupt näher zu treten. Es beschäftigt sich also dieser Teil meiner Arbeit in erster Linie mit der Entwickelung des Markes, und mit der der Rinde nur insoweit, als die Weiterentwickelung nach erfolgter erster Anlage untersucht werden konnte.

Im zweiten, histologischen Teil sollen neue Details über die Zellen der Rinde und des Markes in verschiedenen Lebensaltern zur Besprechung gelangen.

\section{Entwickelung der Rinde.}

Im folgenden sollen zunächst nur jene Arbeiten citiert werden, welche sich mit der Entwickelung der Nebenniere bei Säugern beschäftigen. 
Wir finden in diesen Arbeiten hauptsächlich zwei Angaben vorherrschend: die einen Autoren leiten die Entstehung der Rinde vom zwischen Aorta, Kardinalvene und Wolffschem Körper gelegenen Cölomepithel ab. Zu diesen Autoren gehören: Ecker, Brunn, Koelliker, Valentini u. a.

Nach Mitsukuri soll die Nebenniere aus dem Mesoblast entstehen. Gottschau lässt die Rinde rechts aus einem Kernhaufen an der hinteren Wand der Vena cava sich entwickeln, vielleicht sogar in der Wand selbst. Die linke Nebenniere entwickelt sich in ähnlicher Weise aus der Vena spermatica oder renalis. Ferner kommt er zum Schluss, dass kein Teil der Nebennierenanlage aus dem Sympathicus stamme, da dieser Nern durch feinstes Bindegewebe jederzeit von der eigentlichen Mesodermalanlage der Nebenniere getrennt erscheint.

Janosik untersuchte Kaninchen- und Schweine-Embryonen, und lässt Rinde und Mark aus dem Keimepithel jener Bucht, die der W olff sche Körper mit dem Gekröse bildet, hervorgehen.

Denselben Ursprungsort für die Entwickelung der Rinde nimmt auch Mihalkovicz bei verschiedenen Tieren an; ferner In ab a nach Untersuchungen an der Maus.

Ich glaube, bei Schweineembryonen nachgewiesen zu haben, dass die Rinde aus "dem Leibeshöhlenepithel zu beiden medialen Seiten der Wolff schen Körper entstehe.

Eine ganz neue Ansicht vertritt Aich el: er lässt die Nebenniere höherer Wirbeltiere aus Urnierentrichtern entstehen; von den Rodentia aufwärts entstehe die Nebenniere frei im Mesenchym, doch hält es Aichel für wahrscheinlich, dass auch bei den höheren Säugern die Urnierentrichter bei der Entwickelung der Nebenniere eine entscheidende Rolle spielen.

(Ich habe mich in der Citierung der einschlägigen Arbeiten kurz gefasst, umsomehr, als ausführliche Litteraturangaben in zahlreichen Arbeiten (z. B. A ichels) enthalten sind.)

Über die Entwickelung der Marksubstanz liegen ebenfalls 
zahlreiche Angaben vor, welche ich in meiner Arbeit über die „Entwickelung der Nebenniere des Schweines" ausführlich besprochen habe sodass ich mich hier kurz fassen kann.

Aus dem Sympathicus lassen Balfour, Braun, Hoffmann, Inaba, Kohn, Mitsukuri, H. Rabl, Weldon, van Wijhe und ich die Marksubstanz entstehen, Koelliker und Fusari halten nicht mit voller Bestimmtheit das Mark für ein Sympathicus-Derivat; Janosik, Valenti und Aichel nehmen an, das Mark entwickle sich aus der Rinde; Gottschau ist der Ansicht, das Mark entwickle sich zeitlebens aus der Rinde; Semper und von Brunn leiten das Mark aus dem Bindegewebe $a b$.

Zu meinen Untersuchungen stand mir folgendes Material zur Verfügung:

1. Embryo humanus von $12^{1 / 2} \mathrm{~mm} \mathrm{S.S.}$

2

2. " $", 15 \mathrm{~mm}$

3. " , " $17 \mathrm{~mm}$,

4. " " , $19 \mathrm{~mm}$,

5. " " , $19 \mathrm{~mm}$ "

6. " " , $28 \mathrm{~mm}$,

7. " $, \quad, 51 \mathrm{~mm}$, ,

8. " , , , $60 \mathrm{~mm}$,

9. " " " 95 mm ",

ferner Föten aus dem 6.--8. Monate, zahlreiche (47) Paare von Nebennieren Neugeborener und Objekte aus verschiedenen Lebensaltern.

Ich lasse nun die Beschreibung der einzelnen Stadien folgen.

Menschlicher Embryo S. S. $12^{1 / 2} \mathrm{~mm}$. Querschnittserie von $15 \mu$ Schnittdicke (Abb. 1).

In diesem jüngsten Stadium, das mir zur Verfügung stand, finde ich die Nebennierenrinde bereits angelegt; ich kann infolge- 
dessen über das früheste Auftreten nichts aussagen. Die Neben. uiere stellt ein ca. $1^{1 / 2} \mathrm{~mm}$ langes Organ dar, das beiderseits im oberen Drittel des Wolffschen Körpers beginnend, an diesem in der genannten Länge herabreicht. An der medialen Seite zieht der Nervus Sympathicus herab, der ebenfalls schon gut differenziert ist.

An der lateralen Seite der Nebennierenanlage ist der Wolff . sche Körper gelegen, gegen welchen sich die Nebenniere durch einen schmalen Mesodermstreif abgrenzt. Da also in diesem Stadium die Nebenniere bereits deutlich differenziert erscheint, kann ich die Aichelschen Befunde betreffend den Ursprung der Rinde aus Resten der Urnierenkanälchen weder bestätigen, noch verneinen. Wenn ich aber die Bilder mit jenen vergleiche, die man bei jungen Kaninchen-Embryonen sieht, deren Nebennierenanlage in späteren Stadien, die dem vorliegenden menschlichen Embryo ungefähr entsprechen, genau so gebaut und gelagert ist, wie beim Menschen, so kann ich nicht den Eindruck gewinnen, dass es sich um Derivate der Urnieren-Kanälchen handle. Wir finden nämlich bei Kaninchen-Embryonen von $6,5 \mathrm{~m}$ Länge thatsächlich Einstülpungen, welche jenen identisch sind, die A ichel als Trichter anspricht. Auch die Nebennierenanlage ist vorhanden, aber von diesen Einstülpungen durch $\dot{ }$ - allerdings - ganz schmale, aber doch deutlich sichtbare Mesodermstreifen getrennt, ebenso, wie jederzeit zwischen W olffschem Körper und Nebenniere eine deutliche Zwischenwand sichtbar ist. Man müsste in irgend einem Stadium einen deutlichen Zusammenfluss beider Organe konstatieren können. Ausserdem sind die fraglichen Einstülpungen, die an Serien von Tieren aller Grössen an der lateralen und oberen Seite, auch am distalen Pol des Wolffschen Körpers sichtbar sind, viel zu lang, um als Urnierentrichter imponieren zu können. Ferner fehlt, wie ich schon in einer früheren Arbeit erwähnte, jede Metamerie, welche doch für die Trichter charakteristisch ist, wie aus den Abbildungen Semons 
und aus jeder Schnittserie an Amphibien (sehr schön bei Anurenlarven) erhellt.

Die feinere Struktur der Nebenniere in dem erwähnten Stadium zeigt zunächst, dass eine Differenzierung in einzelne Schichten ebenso vollständig fehlt, wie die Marksubstanz.

Wir finden, das ganze Organ aus durchaus gleichwertigen Zellen aufgebaut, deren Charakteristicum grosse, bläschenförmige Kerne wenig und schwach granuliertes Protoplasma ist; die Form der Zellen ist rundlich, hie und da polyedrisch.

Die Kerne zeigen deutlich Chromatin in Form von Körnern; Karyokinesen konnte ich in keinem einzigen Schnitte sehen. Das Organ ist vaskularisiert und zwar sieht man $\ddot{A}$ stchen von einer Arteria suprarenalis eintreten, Venen münden teils in die Cava, teils in Äste der Lebervenen und durch diese in die Cava. Eine Vena centralis der Nebenniere ist nicht vorbanden. Ausser den spezifischen Zellen, die dicht nebeneinander liegen und weder eine glomerulöse noch retikuläre Anordnung zeigen, findet sich spärliches Bindegewebe. Eine sehr schmale dünne Kapsel begrenzt das Organ nach allen Seiten.

Den Symphathicus sieht man in diesem Stadium als deutlich differenzierten Strang an der medialen Seite der Nebennierenanlagen beckenwärts ziehen. Er zeigt zweierlei Bestandteile: Nervenfasern und jene Zellen, die ich als, sy mpathische Bildungszellen" bezeichnen möchte, da aus ihnen sich später Marksubstanz, Ganglienzellen und chromaffine Körper entwickeln. Über das früheste Auftreten dieser Zellen kann ich nichts aussagen: Jedenfalls scheinen sie sich frühzeitig anzulegen, da ich sie bei Kaninchenfrüchten der ersten Woche bereits finde.

Diese Zellen sind regellos im ganzen Sympathicus sowohl in den Ganglien des Grenzstranges, wie der Geflechte verteilt; sie stammen wohl aus Teilen des Centralnervensystemes, speziell den Spinalganglien; doch deuten zahlreiche Kernteilungsfiguren 
Beiträge zur Anatomie u. Entwickelung d. menschlichen Nebenniere. 489

auch auf Entstehung neuer Zellen nach dem Verlassen des Rückenmarkes hin.

Die Zellen zeigen folgenden Bau: charakteristisch ist für diese Zellen wenig Protoplasma und ein grosser, mit Hämatoxylin sich intensiv färbender Kern. Ihr Durchmesser schwankt von 4-6 $\mu$. Sie liegen teils in Gruppen, teils reihenweise angeordnet, häufig erscheinen Gruppen solcher Zellen durch Nervenfasern miteinander verbunden.

Gegen die Nebenniere hin begrenzt sich der Sympathicus deutlich durch die vorerwähnte dünne Rindenkapsel, keine einzige der Sympathicus-Zellen dringt in das Innere des Organes ein. Unterhalb des Abganges der Art. coeliaca konfluieren die Sympathicus-Zellen und Fasern zu einem grossen Haufen, in dem ich die erste Anlage der grossen abdominalen sympathischen Geflechte erblicke.

Diese Zellen, ganz charakteristisch für den Sympathicus, stellen in diesem Stadium Bildungszellen ganz besonderer Art dar, welche bei Vertretern aller Wirbeltierklassen durchaus gleichartig sind. Vergleicht man die Abbildungen Onodis und C. Rabls bei den Selachiern, die Larven von Amphibien, ferner Embryonen von Reptilien, Vögeln und Säugern, so findet man bei allen dieselbe Anlagekünftiger Sympathicusteile, wie ich sie oben beim Menschen beschrieben habe. Alle Derivate des Sympathicus: Ganglienzellen, chromaffine Organe und Marksubstanz der Nebenniere lassen sich einzig und allein von diesen symathischen Bildungszellen ableiten.

Embryo humanus von $15 \mathrm{~mm}$ Länge. Querschnittserie von $15 \mu$ Schnittdicke.

Das Wachstum der Nebenniere hat insofern zugenommen, als sie breiter erscheint und auch an Läuge gewonnen hat. 
Auch das histologische Bild hat sich geändert. Obwohl die Rindenzellen noch durchwegs ihrem Baue nach gleich sind, beginnt bereits eine Umordnung, indem Zellsäulen auftreten, die von der Peripherie gegen das Centrum zu konvergieren. Doch betrifft diese Anordnung nicht das gauze Organ, sondern an vielen Stellen ist die ursprüngliche Art der Anordnung noch bewahrt. Auch liegen die Zellen nicht mehr so dicht nebeneinander, wie im vorhergehenden Stadium, sondern die einzelnen Säulen begrenzen Zwischenräume, die Kapillaren enthalten. Gegen die Urniere und den medial gelegenen Sympathicus erscheint die Nebenniere noch deutlicher abgegrenzt als im vorhergehenden Stadium, da auch die Kapsel an Dicke zugenommen hat.

Der ausserhalb des Organes liegende nervöse Abschnitt zeigt im grossen und ganzen dieselben Verhältnisse wie beim vorhergebenden Stadium. Bloss die sympathischen Bildungszellen haben an Zahl zugenommen, sodass die Zellhaufen und Ballen dichter und grösser erscheinen. Eine Differenzierung irgend einer Art ist nicht nachweisbar. In der Nebenniere selbst tritt ebenfalls noch nichts von nervöser Substanz ein.

Embryo humanus von $17 \mathrm{~mm}$ SS. Querschnittsserie von $15 \mu$ Schnittdicke (Abb, 2).

Die Nebenniere repräsentiert sich am Schnitte als makroskopisch sehr gut sichtbares Knötchen. Ihre Zellen haben sowohl an Zahl als auch an Grösse bedeutend zugenommen und stellen polygonale oder rundliche Gebilde dar, welche im Zell. verband (besonders an den kaudal gelegenen Partien), schon deutlich zu Säulen angeordnet sind. Die Zellen selbst zeichnen sich durch ihre grossen, bläschenförmigen Kerne aus. Eine Anordnung in die übrigen Zonen der Nebenniere ist nicht vorhanden. Von der Kapsel lassen sich feinste Bindegewebsfasern in das Innere des Organes verfolgen, mit welchen zugleich Gefässe eintreten. 
Die Anlagen des Sympathicus ziehen an der medialen Seite der Nebenniere hinab und greifen am unteren Pol des Organes ein wenig auf die laterale Seite über, sodass dieser Teil der Nebenniere von Bestandteilen des Sympathicus umgegriffen erscheint. Es beginnt nun aber von der medialen Seite her bereits Einwanderung sympathischer Elemente in folgender Weise: Man sieht, dass einzelne Ballen der indifferenten Sympathicusanlagen, die an der medialen Seite der Nebenniere liegen, in das Organ eintreten, indem an verschiedenen Stellen die Kapse] durchbrochen erscheint und in die Lücken grössere und kleinere Zellhaufen getreten sind, die auch bereits einwärts von der Kapsel als äusserste Schichte lagern. Eine Anzahl dieser Haufen hat den Zusammenhang mit dem extrakapsulären Sympathicus bereits aufgegeben, ein anderer hängt mittelst Nervenfasern mit diesem Teil noch zusammen. Diesen Befund macht man in diesem Stadium nur an der medialen Seite des Organs. Die laterale und obere Seite, sowie die central gelegenen Partien sind noch vollkommen frei. Nur an vereinzelten Stellen kann man beobachten, dass sympathische Elemente bereits mehr central gewandert siud, sodass sie durch eine ganz schmale Zone Rindenzellen von der Kapsel getrennt erscheinen. Dieser Befund ist aber, wie ich noch einmal bemerken will, bloss an der medialen Seite zu machen. Die einwandernden indifferenten Sympathicus-Zellen sind zu 4-6 zu Ballen oder Haufen angeordnet; mit ihnen wandern auch SympathicusFasern ein. Dieser Vorgang spielt sich besonders am mittleren und oberen Teil der Nebennierenanlage ab, während am kaudalen Ende noch nichts von einem Einwandern zu sehen ist. Durch das Eindringen sympathischer Elemente werden an einzelnen Stellen kleinere Partien von Rinde abgelöst, indem sie allseitig von einwanderuden sympathischen Bildungszellen umgriffen werden und schliesslich in das Bindegewebe und die Anlagen der künftigen Plexusganglien gelangen. Ich glaube, 
diese Thatsache erklärt das häufige Vorkommen „accessorischer Nebennieren" im Plexus solaris, sowie in nächster Nähe des Hauptorganes; diese accessorischen Nebennieren bestehen aus Rinde oder einem von Sympathicus-Derivaten umgebenen Rinden. kerne oder schliesslich aus Rinde und in dieser enthaltenem Mark. Diese Befunde decken sich vollkommen mit jenen, die an Tieren gemacht wurden, am schönsten mit dem Einwandern sympathischer Elemente, wie ich sie beim Schweine beschrieb. Wenn Aichel behauptet, dass die Sonderung von Mark und Rinde dadurch entstehe, dass in dem ursprünglich gleichartigen Gewebe Bindegewebszüge auftreten, die die Randteile in einzelne Zellhaufen teilen und später im mittleren Teile Gefässe auftreten, die die Zellen der Anlage in Stränge sondern, so möchte ich vorläufig das entgegenhalten, dass Einwandern sympathischer Elemente zugleich mit Bildung des Stromas vor sich geht und dass während der ganzen Embryonalzeit, ja weit über diese hinaus sympathische Elemente einwandern.

Das Stadium, auf welches sich Aichel beruft, zeigt die Marksubstanz allerdings noch nicht ausgebildet. Es sei gleich hier bemerkt, dass sich der Reichtum der Nebenniere an Ganglienzellen mit den kolossalen Massen von einwanderndem Sympathicus nicht deckt und, wie gezeigt werden wird, die Entwickelung der Marksubstanz aus den einwandernden Bildungszellen direkt beobachtet werden kann.

Embryo humanus. $19 \mathrm{~mm}$ SS. Horizontalserie $15 \mu$.

Das Organ hat sowohl an Länge als an Breite zugenommen. Das Bild der Rinde deckt sich mit dem im vorhergehenden Stadium im allgemeinen, bloss die Unordnung in Zellsäulen ist fortgeschritten. Die central gelegenen Rindenpartien zeigeu einen mehr netzförmigen Bau als früher, da zwischen ihnen reichljch Blutgefässe sich entwickelten. Auch die erste Anlage 
Beitrăge zur Anatomie u. Entwickelung d. menschlichen Nebenniere. 493

einer Vena centralis in Form eines kleinen, mit Blutkörperchen gefültten Lumen ist vorhanden. Der feinere Bau ist derselbe geblieben, wir finden noch immer einheitlich polygonale oder runde Zellen. Auf eine besondere Art der Zellanordnung knapp einwärts von der Kapsel soll weiter unten aufmerksam gemacht werden.

Die Dichtigkeit der Zellballen und Stränge im Sympathicus hat an seinem ganzen hier in Betracht kommenden Abschnitt bedeutend zugenommen. In die Nebenniere wandern grosse Partien der sympathischen Zellen ein und lagern teils als peripherste Zone, teils etwas weiter centralwärts, ohne aber das Centrum zu erreichen. Die innerhalb des Organes liegenden sympathischen Haufen sind deutlich zu Ballen angeordnet, ganz ähnlich wie es Kohn als erste Anlage der Carotisdrüse beschreibt. - Ausserdem finden wir knapp innerhalb der Kapsel, fast an allen Stellen des Organes, vereinzelte Sympathicus-Bildungszellen liegen, welche während des ganzen Verlaufes der Entwickelung und auch nach der Geburt, vielleicht zeitlebens ${ }^{1)}$ an Ort und Stelle liegen bleiben und einen stärker tingierten Saum bilden. Diese Zellen liegen im bleibenden Zustande ausserhalb der Zona glomerulosa, zwischen dieser und der Kapsel und können, wenn man nicht die Entwickelung der Zonen genau verfolgt, leicht übersehen oder mit Rindenzellen der sich stark färbenden Zona glomerulosa verwechselt werden.

Die Einwanderung sympathischer Elemente erfolgt hauptsächlich von der medialen Seite her. Ausserdem lässt sich aber ein ziemlich breiter, von zelligen Elementen reichlich durchsetzter Strang über die Mittellinie hinaus am unteren Pole der Nebenniere bis gegen die laterale Seite hin verfolgen, aus welchem

1) In fast allen untersuchten Exemplaren Erwachsener konnte ich diese Zellform nachweisen. 
Sympathicusabschnitte ebenfalls Teile einzuwachsen beginnen. Der lateralste, gegen die seitliche Rumpfwand zu liegende Anteil des Organes ist vollkommen frei von sympathischen Elementen. Eine Umbildung der innerhalb des Organes liegenden Sympathicusbestandteile $\mathrm{zu}$ definitiver Marksubstanz ist in diesem Stadium nicht zu verfolgen.

Embryo humanus von 28 mm Querschnittserie von $15 \mu$ Schnittdicke.

Die Rindensubstanz erscheint in diesem Stadium bereits deutlich in drei Zonen gegliedert, die sich nur durch die Anordnung der Zellen unterscheiden. Alle Zellen sind polygonal, seltener rundlich; alle besitzen einen grossen bläschenförmigen Kern mit deutlich sichtbaren Chromatinkörnern. Die periphere Schichte ist diejenige, in welcher die Zellen dicht angeordnet, das bilden, was Zona glomerulosa genannt wird. Sie ist nichts anderes als die Stelle, wo die Zellsäulen der Zona fasciculata umbiegen. An vielen Stellen fehlt die Zona glomerulosa vollständig; dann reichen die Cylinder der Zona fasciculata bis knapp an die Kapsel, von ihr an vielen Stellen durch Häufchen von Sympathicus-Bildungs-Zellen geschieden. Die fascikuläre Schichte ist weitaus die breiteste des ganzen Organes; gegen das Centrum zu weichen die Zellsäulen auseinander und lassen Lücken zwischen sich, wodurch das gebildet wird, was man Zona reticularis nenut. Diese bildet den centralen Teil der Nebenniere; ihre Zellen finden wir auch um die Vena centralis angeordnet.

In diesem Stadium ist auch bereits an vielen Stellen das Reticulum sichtbar, in welchem die einzelnen Zellen nicht, wie es vielfach behauptet wurde, frei, sondern deutlich abgeschlossen liegen.

Zuckerkandl sagt von diesem Embryo in Bezug auf den Sympathicus, dass die Differenzierung in Geflechtganglien 
und chromaffine Körper durchgeführt ist, indem ,in der Nachbarschaft der Aa. coeliaca und mesenteria superior im sympathischen Geflecht dunkel gefärbte Körper mit dicht gedrängten Zellen sich finden; unterhalb des Abganges der Mesenterica superior aber treten an den embryonalen Geflechtsganglien zweierlei Gewebe auf, a) eine dunkel gefärbte, von einstrahlenden Nerven durchsetzte, welche die eigentliche Anlage der Plexusganglien darstellt (dorsal), und b) lichter gefärbte Körper (ventral), welche den Nerven beziehungsweise Ganglien nur anliegen und sich durch ihren Bau von den Anlagen der Plexusganglien unterscheiden; ihre Zellen und deren Kerne sind grösser und die Zellkörper schwächer gefärbt als in den Plexusganglien". Wir finden demnach in diesem Stadium in den ausserhalb der Nebenniere befindlichen Sympathicusabschnitte zwei Bestandteile: eigentliche sympathische Zellen, die die Plexusganglien bilden und die chromaffinen Zellen, da nur diese allein es sind, die von allen sympathischen Zellen diese Chromreaktion geben, gleichgiltig ob sie frei oder in den Plexusganglien oder schliesslich in der Nebenniere liegen.

Was die sympathischen Elemente betrifft, die in letzteres Organ einwandern, so mag sofort vorweg genommen werden, dass differenzierte chromafine Zellen, also Teile der Nebenkörper nicht einwandern. Die Einwanderung beschränkt sich einzig und allein auf noch undifferenzierten Sympathicus, obwohl chromaffine Elemente in nächster Nähe der Nebenniere liegen, von ihr durch eine äusserst schmale Mesodermpartie getrennt, die an manchen Schnitten nur mit sehr starker Vergrösserung wahrnehmbar ist, sodass es bei nicht sehr genauer Durchsicht der Schnitte oft den Eindruck macht, als würden differenzierte Sympathicusteile innerhalb der Nebenniere lagern, ähnlich einwandernd, wie die noch undifferenzierten Sympathicuszellen. Nur diese wandern noch immer und in grosser Menge ein, sodass bereits viel Sympathi- 
cus innerhalb der Nebenniere liegt, ohne aber das Centrum zu erreichen. An vielen Stellen besteht ein breiter Zusammenhang mit noch ausserhalb des Organes liegenden sympathischen Bestandteilen. Eine Differenzierung in echte, sympathische Ganglienzellen konnte in diesem Stadium nicht verfolgt werden. Die sympathischen Bestandteile liegen vollkommen regellos zerstreut im ganzen Organ, besonders dicht im mittleren Drittel. Der peripherste Teil der Nebenniere besteht grösstenteils aus Rinde, ausnahmlos das Centrum.

Dass Teile der chromaffinen Nebenkörper in die Nebenniere einwandern, glaube ich nicht, da diese hochdifferenzierten Gewebe wohl kaum noch einwanderungsfähig sind. Damit stimmt auch, dass innerhalb der Kapsel, etwas centralwärts von dieser, wie mit Bestimmtheit behauptet werden kann, in diesem Stadium keine einzige chromaffine Zelle gesehen wurde. Noch mehr scheint mir der Unstand zu sprechen, dass, wie gezeigt werden wird, die Differenzierung chromaffiner Elemente, zur definitiven Medullarschicht, viel später, grösstenteils erst nach dem Fötalleben, ja sogar erst im Verlauf der ersten Lebensjahre erfolgt.

Embryo humanus von $51 \mathrm{~mm}$ SS. Querschnittserie von $15 \mu$ Schnittdicke.

In Bezug auf die Rindensubstanz lässt sich für das vorliegende Stadium wenig Neues sagen. Die Anordnung in die bleibenden drei Zonen ist fortgeschritten und lässt sich bereits am ganzen Organe nachweisen. Sehr deutlich ist die Zona glomerulosa ausgebildet, welche breiter erscheint als in irgend einem späteren, ja selbst breiter als post partum. Ob für diesen Umstand individuelle Verhältnisse in Betracht zu ziehen sind, glaube ich annehmen zu dürfen, da Ausbildung, Grösse und 
Beiträge zur Anatomie u. Entwickelnng d. menschlichen Nebenniere. 497

Vorhandensein dieser Rindenschichte nicht nur innerhalb verschiedener Tierklassen, sondern auch bei Vertretern derselben Species variiert. Immerhin ist ihre Breite in einem verhältnis. mässig so jungen Embryonalstadium auffallend. Die breiteste Zone ist die mittlere, Zona fasciculata. Gegen das Centrum finden wir wieder eine Zona reticularis.

Zwischen den Rindenzellen, peripher gelegen, finden wir Sympathicusbildungszellen, die den Zusammenhang mit ausserhalb der Rinde gelegenen Partien grösstenteils aufgegeben haben. In mehreren Stellen sieht man ziemlich dichte Nervenstränge mit eingelagerten Bildungszellen aus dem Sympathicus in die Nebenniere hineinziehen. Aber die zum grössten Teil noch randständigen Partien der eingewanderten Sympathicusezllen sind an vielen Stellen eine bemerkenswerte Umwandung eingegangen, sie haben sich zu chromaffinen Zellen verwandelt. Wir finden nämlich folgendes: Die $\mathrm{Zucker}$ kandlschen Nebenorgane, die mächtige Zellenkomplexe bilden, reichen bis hart an die Kapsel der Nebenniere heran, da sich viel von den undifferenzierten Sympathicuszellen, die bis jetzt an der medialen Seite der Nebenniere lagerten, sich in chromaffine Zellen resp. Organe umwandelten. Ich nenne diese Zellen, die in der Nebenniere lagern, und sich aus dem Sympathicus in einer unten zu beschreibenden Weise differenzieren, deshalb chromaffin, weil diese Zellen, deren Entwickelung auch in späteren Lebensaltern sich deutlich verfolgen lässt, die spezifische Chromreaktion geben und ihrem ganzen Bau und Verhalten nach den bereits von anderen Autoren beschriebenen chromaffinen Zellen gleichen, besonders aber den Zellen der sympathischen Nebenkörper. Über das erste Auftreten der Chromreaktion bei Embryonen kann ich nicht aussagen, da das Untersuchungsmaterial in keiner geeigneten Fixierungsflüssigkeit gelegt wurde, zum grössten Teile mir als fertige Serie zu Gebote stand. 
Wir finden demnach in diesem Stadium ausserhalb und was für die vorliegende Frage wichtig ist, auch innerhalb der Nebenniere zweierlei Sympathicusbestandteile: 1. sympathische Bildungszellen in Form von Ballen und Zellhaufen und 2. chromaffine Zellen, ebenfalls in Haufen und Ballen, teilweise auch in Form von zwischen den Rindenzellen gelagerten Strängen. Übergangsstellen zwischen beiden Zellsorten finden sich in spär. licher Menge, weil eben nur ein geringer Teil der eingewanderten sympathischen Elemente sich umbildete. (Die genauere Beschreibung dieses Vorganges erfolgt erst später bei Besprechung der Verhältnisse des $95 \mathrm{~mm}$ langen Embryo.) Vorläufig sei soviel gesagt, dass wir neben den undifferenzierten, noch immer wie lymphoides Gewebe aussehenden Sympathicusballen Zellhaufen finden, die sich durch ibr helles Protoplasma, den grassen blasenförmigen Kern deutlich von den übrigen Sympathicuszellen einerseits, andererseits von den Rindenzellen unterscheiden. Sie liegen in variabler Anzahl (bis zu dreissig konnte jch zählen) iu einer bindegewebigen äusserst feinen Kapsel oder frei zwischen den Rindenzellen. Dort, wo sie in kleinen Ballen liegen, liegen sie in feinen Maschen eines Reticulum, hier und da durchsetzt ein Gefässchen den ganzen Komplex. Man findet auch folgende Form: Gegen die Peripherie einen Ballen, der aber nicht in sich abgeschlossen erscheint, sondern sich als schmaler Strang centralwärts eine Strecke weit in das Organ hinein verfolgen lässt. Diese umgebildeten Sympathicusteile liegen sowohl knapp einwärts von der Kapsel, als auch im mittleren Drittel des Organes, sowie zwischen dieser Breite, nirgends aber central. Die centralere Partie bildet noch immer die netzförmige Rindenschicht. Es sei noch erwähnt, dass sich auch in diesem Stadium keine einzige Stelle nachweisen lässt, aus der zu entnehmen wäre, dass Teile der ausserhalb der Nebenniere liegenden chromaffinen Körper einwandern. 
Embryo hum. von 60 mm SS. Querschnittserie.

An allen jenen Stellen, die im vorher beschriebenen Stadium noch nicht zu den Zonen der Rindensubstanz umgebildet waren, zeigt sich bereits der definitive Zustand in Bezug auf Anordnung und gröberen histologischen Bau. Aber andere Veränderungen in den Zellen der Rinde, die sich nach der Geburt zeigen und auf besondere funktionelle Zustände hinzudeuten scheinen, sind in diesem Stadium nicht sichtbar. Es zeigt sich aber jedenfalls, dass die endgiltige Formierung des epithelialen Abschnittes er reicht ist und die ferneren Veränderungen hauptsächlich im nervösen Abschnitte sich abspielen.

Was zunächst den ausserhalb der Nebenniere liegenden Sympathicusabschnitt betrifft, so ist zu sagen, dass sich ein grosser Teil des Sympathicus (Bildungsmaterial) zu chromaffinen Körperchen umbildete, während der andere noch auf dem embryonalen Zustand des indifferenten Sympathicus beharrt. Bei diesem Embryo liess sich aber ein interessanter Befund machen; einer von den im Plexus liegenden chromaffinen Körperchen zeigt nämlich an seiner Peripherie eine schmale Zone unverkennbarer Rindenzellen, während an mehreren anderen Stellen in nächster Nähe des Hauptorganes kleine Partien von Rindenzellen fre (manchmal umgeben von indifferentem Sympathicus) im Plexus lagern. Diese Partien stellen accessorische Nebennieren dar, deren Entstehung ich schon früher andeutete.

Im selben Masse als die ausserhalb liegenden sympathischen Elemente sich umbildeten, gehen auch Veränderungen innerhalb der Nebenniere vor sich. Eine Anzahl von Sympathicushaufen sind weiter centralwärts gewandert und liegen an einzelnen Stellen auch schon ganz central, aber nicht als einheitliche Masse, sondern durch grosse Partien von Rindenzellen voneinander getrennt. Jeder Sympathicushaufen ist von Rindenzellen kappenartig umschlossen, ganz analog, wie ich dies beim Schweine be- 
schrieben und abgebildet habe. Ausserdem finden wir noch reichliche Bildungszellen an der Peripherie als äusserste Zone, sowie auch an allen Stellen zwischen Peripherie und Centrum verteilt, so dass das ganze Organ von nervösen Elementen durchsetzt erscheint.

Inzwischen haben sich weitere chromaffine Elemente aus den Bildungszellen des Sympathicus herausdifferenziert, wenn auch noch immer der grösste Teil auf dem ursprünglichen Zustand verharrt. Wir finden Marksubstanz in Form von Strängen zwischen den Rindensäulen, oder als kleine Häufchen, aber dieselben haben noch keineswegs das Centrum erreicht, sondern beschränken sich vorzüglich auf die peripheren Organpartien. Jedenfalls ist auffällig, dass die Umbildung nur langsam vor sich zu gehen scheint, speziell im Vergleiche mit den schon völlig ausgebildeten chromaffinen Nebenorganen des Retroperitonealraumes. Die Hauptmasse der Differenzierung erfolgt eben in einem späteren Stadium und es scheint, als ob die chromaffinen Nebenkörper in der Embryonalzeit und auch noch über diese hinaus die Funktionen des nervösen Nebennierenabschnittes übernehmen, wie auch die Rückbildung dieser Körper mit der völligen definitiven Ausbildung der Marksubstanz im Zusammenhang stehen dürfte. - Wir finden also auch noch in diesem Stadium sowohl und in grösserer Menge sympathische Bildungszellen als auch bereits umgewandelte nervöse Substanz.

Die Einwanderung neuer sympathischer Bildungselemente ist bedeutend geringer geworden; nur an wenigen Stellen sehen wir solche die Kapsel durchsetzen oder innerhalb liegende Elemente mit ausserhalb liegenden in Verbindung. Feine Nervenfäden dagegen lassen sich von aussen nach dem Innern deutlich verfolgen. 
Beiträge zur Anatomie u. Entwickelung d. menscblichen Nebenniere. 501

Embryo hum. $95 \mathrm{~mm}$. Retroperitonealraum.

Querschnittserie. (Abb. 3).

Ueber den Bau der Rinde lässt sich wenig Neues mehr sagen, da ihr endgültiges Aussehen bereits erreicht ist. Auffallend ist auch in diesem Falle bloss die relative Breite der Zona glomerulosa.

Sehr schön ist die Umwandlung der sympathischen Bildungszellen in die definitive Marksubstanz zu verfolgen. Es wandert nocb immer, wenn auch in beschränktem Masse sympathische Substanz in die Nebenniere ein.

Ein grosser Teil hat das Centrum bereits erreicht, ein anderer liegt zerstreut im ganzen Organ. Nun ist aber die Differenzierung so weit gediehen, dass die die Sympathicushaufen trennenden Zellen nur zum geringeren Teil (soweit es die centralen Partien anlangt) Rindenzellen sind; wir finden nämlich zwischen ihnen die bereits umgebildeten, zum Teil sich auch erst umbildenden Derivate der Bildungszellen.

Während in früheren Stadien die Zellhaufen den einheitlichen an lymphoides Gewebe erinnernden Anblick boten, sehen wir mitten in diesen Haufen Zellen auftreten, die ein helles, kaum mit Eosin gefärbtes Protoplasma und einen grossen, bläschenförmigen Kern besitzen. An anderen Stellen hat die Differenzierung schon so weit Platz gegriffen, dass das ganze Häufchen bis auf 2-3 Zellen sich umbildete, so dass wir einen Ballen umgebildeter sympathischer Zellen vor uns haben, der nur noch wenige Bildungszellen erhält. Zwischen der vollständigen Umwandlung und dem Auftreten von wenigen chromaffinen Zellen im Bildungsgewebe finden wir alle möglichen Übergänge. In den centralen Anteilen ist die Umwandlung schon ziemlich weit gediehen, so dass wir jetzt von wirklicher Marl substanz sprechen können. 
Die umgebildeten Zellen treten auch in Form von Strängen auf, indem einzelne Häufchen nicht isoliert, sondern reihenweise angeordnet erscheinen. Auch an der Peripherie finden wir, be. sonders deutlich in der Zona glomerulosa kleine Ballen umgebildeter Zellen, nebenan finden sich Häufchen sympathischer Bildungszellen. Die Zellen sind ebenso gebaut wie die chromaffinen Zellen des Sympathicus überhaupt, vor allem sehr ähnlich den Zellen, wie sie Zuckerkandl für die Nebenkörper des Sympathicus beschreibt.

Ich finde auch in diesem Stadium keine fertigen Ganglienzellen innerhalb der Nebenniere, obwohl viele Nerven mit zelligen Elementen durchsetzt in die Nebenniere ziehen, während in den ausserhalb der Nebenniere liegenden Geflechtganglien bereits differenzierte Ganglienzellen zu beobachten sind.

Die beschriebenen Vorgänge dauern während der ganzen folgenden Embryonalperiode fort. Aber innerhalb der Fötalperiode ist die völlige Ausbildung der Marksubstanz keineswegs als abgeschlossen zu betrachten, dieselbe zeigt eine postembryonale Entwickelung, und erst spät ist der definitive Zustand erreicht. Es jst sogar nicht auszuschliessen, dass zeitlebens Umbildungsvorgänge statthaben, wofür manche Gründe sprechen, auf die ich weiter unten zu sprechen kommen werde. Ich halte es daher für überfiüssig, die weiteren Embryonalstadien noch genauer zu berücksichtigen, da die Vorgänge, wie sie früher geschildert wurden, fortdauern, indem sich immer neue sympathische Bildungszellen zu chromaffinen Markzellen umbilden. Aber, wie schon erwähnt, nicht alle und bei verschiedenen Individuen in verschiedener Weise, so dass die Nebenniere des Neugeborenen (soweit es die Marksubstanz betrifft) vollständig von einander abweichende Bilder liefert, indem einerseits noch der grösste Teil der sympathischen Bestandteile auf seinem ursprünglichen Aussehen beharren kann, andererseits auch die Umbildung vollzogen zu sein scheint. 
Beiträge zur Anatomie u. Entwickelung d. menschlichen Nebenniere. 503

Beim Neugeborenen hält die Masse des noch undifferenzierten Sympathicus der des umgebildeten das Gleichgewicht. Allerdings möge gleich hervorgehoben werden, dass wir keinerlei Berechtigung haben, von einer Marksubstanz im strengsten Sinne des Wortes zu reden, also von einer Masse, die rein central gelagert ist; wir finden vielmehr eine ununterbrochene Kette von Sympathicus-Bestandteilen - differenziert und undifferenziert - von der Kapsel bis in das Centrum in Form unregelmässiger Ballen und Stränge, wenn auch das Maximum nervöser Substanz sich im Centrum findet.

Ausserdem finden wir reichliche Partien von Rindenzellen im dichteren centralen nervösen Teil. Neben den chromaffinen Elementen sieht man Ganglienzellen, aber niemals frei zwischen den Markzellen, sondern stets in Nerven eingelagert, ähnlich wie in den Plexusganglien. Die Markzellen selbst unterscheiden sich in nichts von anderen chromaffinen Zellen, nicht einmal durch ihre Anordnung. Man sieht sie in Gruppen zu 4-10 innerhalb einer Bindegewebskapsel, sich deutlich von den Rindenzellen unterscheidend. Übergangsformen aller Art sind nachzuweisen: in einem Häufchen sympathischer Bildungszellen eine und die andere chromaffine Zelle, oder einen Haufen chromaffiner Zellen mit wenigen Bildungszellen u. s. w. Während an den peripheren Nebennierenpartien Übergangsformen seltener zu beobachten sind, finden wir sie reichlich in den centralen Teilen, so dass ich zur Ansicht neige, dass wohl der grösste Anteil der Umbildung erst in den centralen Partien erfolgt, dass alsò chromaffine Zellen als hochorganisierte Elemente nur zum geringen Teile wanderungsfähig sind, sondern dass zur Einwanderung grösstenteils bloss Bildungszellen verwendet werden. Allerdings finden sich differenzierte Zellen in den peripheren Partien, aber nur in spärlicher Menge.

Ich habe einigemal an Nebennieren Neugeborener und auch einmal an einer solchen eines 4 jährigen Kindes eine ganz 
eigentümliche Anordnung der Rindenzonen gefunden, wie sie meines Wissens noch nicht beobachtet wurde. Es zeigte sich nämlich folgendes: Die äusserste Rindenschichte bildet eine Zona glomerulosa; darauf folgte in gewöhnlicher Breite eine Zona fasciculata und auf diese, central gelegen, und um einen Nerven oder eine Arterie kreisförmig angeordnet, wieder eine breite Zona glomerulosa. Die Zona reticularis fehlt vollständig, in einem Falle war auch keine Marksubstanz vorhanden, so dass die Zona glomerulosa thatsächlich rein central gelegen ist.

Immer finde ich sie in diesen Fällen um einen Nerven oder ein Gefäss angeordnet.

Bei einem vierjährigen Kinde konnte ich folgenden Befund machen: In der central gelegenen Marksubstanz liegt ein ziemlich grosses Stück Rinde, eine schmale Stelle ausgenommen, wo es, mit der übrigen Rinde (Zona fasciculata) zusammenhängend, von Mark umgeben ist; dieser Rindenzapfen besteht au seiner peripheren Partie aus Fasciculata-Zellen, während der centrale von einer Zona glomerulosa gebildet wird, die um eine Arterie und Vene angeordnet ist (Abb. 8). Ieh stelle mir das Zustandekommen dieser eigentümlichen Anordnung folgendermassen vor: Beim embryonalen Einwandern von Sympathicus, Gefässen und Nerven wachsen die an diesen Gebilden sich anlegenden Rindenzellen mit in das Innere, sodass also förmlich eine Einstülpung der peripheren Partien gegen das Centrum hin stattfand. Gestützt wird diese Annahme durch die Beobachtung, dass die Zellen der Glomerulosa oft eine breite Schichte bilden, die, allerdings ohne den Zusammenhang mit dem eigentlich peripher gelegenen Teil aufgegeben zu haben, längs eines Nerven oder eines Gefässes sich ziemlich tief ins Organ hineinzieht. Wenn diese miteinwachsenden Zellen der Glomerulosa den Zusammenhang mit der Hauptzone verlieren, können Bilder zustande kommen, wie ich sie eben beschrieb. 
Beiträge zur Anatomie u. Entwickelnng d. menschlichen Ncbenniere. 505

Während die Rindenzellen im Verlaufe der weiteren Entwickelung keine auffallenden Veränderungen zeigen, als die durch die Sekretion bedingten, kann man in Bezug auf die Marksubstanz von einem postembryonalen Wachstum, resp. für einen Teil derselben von einer postembryonalen Entwickelung sprechen. Wir finden nämlich, dass bei jungen Individuen ${ }^{1}$ ) nicht nur inmer neue Markmassen gebildet werden, sondern auch noch neue Sympathicus-Bildungszellen einwandern.

Ich führe als obere Grenze ungefähr das 10. Lebensjahr an, obwohl auch in späteren Jahren an vereinzelten Stellen noch immer Umbildungserscheinungen vorkommen, ja selbst bei Nebennieren alter Individuen sich an einzelnen Exemplaren zeigen lasisen. Im grossen und ganzen aber hat sich die Hauptmasse des eingewanderten Sympathicus zu chromaffinen Elementen umgebildet, die, central gelegen, als Marksubstanz zu bezeichnen sind. Allerdings liegen in allen Fällen zwischen der Marksubstanz Rindenzellen, einzeln oder zu Haufen gruppiert (Abb. 4), ebenso wie Markpartien in Form von Strängen und auch einzelnen Zellen bis an die Peripherie reichen. Es ist deshalb im strengsten Sinne des Wortes nicht erlaubt, von einer Marksubstanz als einem von Rindenelementen vollständig freiem Nebennierenbestandteil zu sprechen, ebensowenig wie von einer „Rinde“. Beide Teile sind zeitlebens nicht voneinander völlig zu scheiden, sondern stellen ein Organ dar, dessen nervöser $A b$ schnitt seiner Hauptmasse zwar das Centrum occupiert, aber keineswegs auf dasselbe beschränkt ist. Die Umbildung der Sympathicus-Bildungszellen zu chromaffinen Elementen scheint - wie ich schon oben erwähnte - Hand in Hand zu gehen mit der Rückbildung der sympathischen Nebenorgane, die als mächtige Organe beim Embryo vorhanden, auch so lange postembryonal persistieren dürften, bis der nervöse Abschnitt der Nebenniere seiner Hauptmasse nach ausgebildet ist.

1) Ich habe Individuen von 1.-10. Lebensjahren daraufhin untersucht. 
Zum Nachweise, dass die chromaffine Zelle jener Bestandteil ist, aus welchem der nervöse Abschnitt sich aufbaut, ist es notwendig, einige Worte über die histologische Technik, die hier in Betracht kommt, zu verlieren. Es ist vor allem wichtig, dass nicht alle Chromgemische in gleich schöner Weise die Reaktion geben. Ebenso wichtig ist die Tinktion. Ich habe alle Gemische, die Chrom und Chromate enthalten, versucht und gebe jetzt folgender Mischung, die etwas von der von Kohn gegebenen abweicht, ebenso wie von der von Hultgren und Andersson angegebenen, den Vorzug.

Ich fixiere ziemlich kleine Stücke bis zu ganzen Organen in folgendem Gemisch:

$$
\begin{array}{ll}
5 \% \text { Kalium bichromicum } & 10 \text { Teile } \\
10 \% \text { Formaldehyd } & 20 \text { Teile } \\
\text { Aq. destill. } & 20 \text { Teile. }
\end{array}
$$

In diesem Gemische bleiben die Stücke je nach Grösse $1-4$ Tage, um sodann in eine reine $5^{\circ} ; 0$ ige Kalium bichromicumLösung übertragen $\mathrm{zu}$ werden, in der sie ebenfalls 1-2 Tage bleiben. Nachher sehr gründliches Auswaschen im fliessenden Leitungswasser (24 Stunden), - nicht ausgewaschene Stücke sind fast immer unbrauchbar - dann Übertragen in 50\% Alkohol, ferner aufsteigender Alkohol, Toluol-Paraffin und Einbettung. Die Stücke haben nach der Fixation eine dunkelbraune Farbe, am Durchschnitte zeigt sich die Marksubstanz als fast schwarzer Streifen. So vorbehandelte Präparate geben nicht nur die Chromreaktion aller so reagierenden Zellen sehr schön, sondern sie sind auch für alle Arten histologischer Untersuchung zu verwenden, da alle Färbungen nach dieser Titration ausgezeichnet gelingen. Bei Präparaten, die ich zur Konstatierung, wie lange die Reaktion gelingt, bis zu 24 Stunden nach dem Tode des betreffenden Individuums fixierte, gelang die Reaktion nicht, wenn auch die Zellen verhältnismässig gut erhalten geblieben waren. - Innerhalb der 1.-12. Stunde nach dem Tode gelingt 
die Methode inmmer. Die übrigen Chromgemische leisten bei weitem nicht so gutes, wie die oben angegebene, am wenigsten gutes die Müllersche Flüssigkeit. Es empfiehlt sich nicht, für Übersichtspräparate allzu dünne Schnitte anzufertigen, da bei diesen die Gelbfärbung undeutlich ist, man kann mit $10 \mu$ vollständig auskommen. Bereits am ungefärbten Präparate wird man die deutliche Gelbfärbung sehen. Für die Färbung mögen jene Farben vor allem gewählt werden, die eine möglichst starke Differenzierung des Plasmas gestatten; häufig ist eine blosse Kernfärbung (z. B. Hämatoxylin) vollständig ausreichend. Als besonders empfehlenswert möchte ich zwei Farben anführen: das Wasserblau und das Toluidinblau. Es zeigte sich nämlich, dass nach Fixation mit Chromaten die chromaffinen Zellen in ibrem plasmatischen Anteil eine deutliche Grünfärbung nach Behandlung mit diesen Farbstoffen zeigen, welche Reaktion wohl aus dem optischen Eindruck, den Blau und Gelb macht, resultieren dürfte.

Diese Grünfärbung tritt selbst in ganz dünnen Schnitten $(3-4 \mu)$ deutlich zu Tage, wo die Gelbfärbung wegen allzu grosser Dünne des Chromniederschlages nicht mehr zu sehen ist. Ich verwende Toluidinblau und Wasserblau in folgender Weise: Die mit Wasser aufgeklebten Schnitte kommen zunächst in eine $1 \%$ Wasserblau- oder $1 \%$ Toluidinblau-Lösung in destilliertem Wasser. In dieser Farblösung verweilen sie 20 Minuten, um nach kurzem (5 Minuten) Verweilen in Leitungswasser mit einer $1 \%$ igen wässerigen Safraninlösung nachgefärbt $z u$ werden (ebenfalls 20 Minuten). Darauf Differenzierung mit Alkohol $95^{0} \%$ u. absolutus, bis die blaue Farbe wieder zum Vorschein kommt, hierauf Karbolxylol, Xylol und Balsam. Das Protoplasma sämtlicher Zellen mit Ausnahme der chromaffinen hellblau, das Plasma dieser hell- bis grasgrün. Kerne rot. Diese Methode führt bei aller Einfachheit zu guten Resultaten. (Abb. 5.) 
Bei allen Präparaten, die derartig behandelt wurden und von Individuen nach dem 10. Lebensjahre stammen, zeigte sich folgendes: Die Markzellen der menschlichen Nebeunieren sind fast ausnahmslos chromassive Zollen. Wir finden die Zellen immer zu Gruppen angeordnet, welche mit mehreren anderen zu Ballen angeordnet sind, sodass ein Bild zustande kommt, das einer Drüse, z. B. einer Speicheldrüse gewissermassen ähnelt. Die Zellen selbst sind rund, manchmal auch spitz an einer Seite, mit hellem, Chromsalze aufnehmenden Protoplasma und grossem, bläschenförmigen Kern. Die Zellen haben abex durchaus nicht alle ein sich vollständig gleichmässig zeigendes Protoplasma; wił finden Kellen, die weniger gelb gefärbt sind, abwechselnd mit direkt braunen Zellen. Dieser Unterschied zeigt sich nicht nur an Zellen, die weit von einander liegen, sondern auch bei Gruppen, wo die eine Zelle dunkel und die Nachbarzelle weniger dunkel oder hell ist. Die besonders dunklen Zellen findet man am häufigsten um die Gefässe gruppiert, mehr von diesen entfernt vorzüglich hellgelbe.

Die Zellhaufen sind wie bekannt durch Gefässe und Bindegewebe voneinander getrennt.

Ganglienzellen finden sich immer nur im Verlaufe von Nerven. An gelungenen Präparaten nach der $\mathrm{N}$ isslschen Methode konnte ich beim Erwachsenen höchstens 10-12 Ganglienzellen an einem Querschnitte zählen, sie sind also im Vergleich zu der grossen Masse der anderen Sympathicusderivate in der Minderheit. Über die Nervenversorgung in und um die chromaffinen Zellen kann ich nichts aussagen, da ich keine einwandsfreien Präparate herstellen konnte. Ich habe an vielen Präparaten den Eindruck gewonnen, dass das, was man als frei im Mark liegende Ganglienzellen bezeichnet, nicht's anderes sind als vereinzelte Rindenzellen, die häufig schwer zu unterscheiden sind von Ganglienzellen, besonders bei nicht spezifischen Tinktionen. 
Beiträge zur Anatomie u. Entwickelung d. menschlichen Nebenniere. 509

\section{Zusammenfassung.}

Die Entwickelung der Mark- oder nervösen Substanz der menschlichen Nebenniere lässt sich, wie ich nachgewiesen zu haben glaube, in zwei Stadien einteilen: 1. Einwanderung sympathischer Bildungszellen in das innere des epithelialen Bestandteils und 2. Umbildung der eingewanderten Teile zu chromaffinen Zellen, beziehungsweise Ganglienzellen. Ich halte es für überflüssig, alle jene Angaben von Autoren, die die Nebenniere vom Sympathicus ableiten, hier wieder zu verzeichnen, da ich einerseits eine ausführliche Litteraturbesprechung in meiner Arbeit über die Entwickelung der Nebenniere des Schweines gegeben habe, andererseits eine ebensolche speziell in der Arbeit Aichels enthalten ist. Ich will mich darauf beschränken, speziell der Ansicht des letztgenannten Forschers hier näher zu treten.

A ichel wendet sich zunächst gegen $H$. Rabl, welcher ebenfalls die Entwickelung der Marksubstanz aus dem Sympathicus hervorgehoben hat und führt an, ,dass die Sonderung des Nebennierengewebes in Mark und Rinde erst sehr spät auftritt, zu einer Zeit, wo von einem Einwandern von Zellen aus dem Sympathicus nicht mehr gesprochen werden darf, in einer Zeit, in der die Nebenniere nach allen Richtungen hin durch eine Kapsel scharf begrenzt ist." Diese Meinung teilt Aichel mit früheren Autoren. Die Behauptung: eine Sonderung in Mark und Rinde tritt erst spät auf, ist richtig, da blos die, Bildungszellen des Sympathicus gegen das Centrum einwandern und zerstreut an allen peripheren Stellen des Organes liegen bleiben und erst viel später durch einen Umwandlungsprozess zu Markzellen werden, die central liegen. Es können daher im mittleren Anteil der Nebenniere in so frühem Stadium, wie beim Aichelschen Maulwurfembryo von $12 \mathrm{~mm}$, Zellunterschiede fehlen und die eingewanderten Sympathicus-Bestandteile an der Peripherie zerstreut lagern. Meine Befunde an Säugetieren und dem 
Menschen decken sich vollkommen mit jenen H. Rabls bei den Vögeln, welcher ausdrücklich sagt, dass das Lageverhältnis bei den drei Klassen der Amnioten auf ein successives Einwachsen hinweise, indem das Mark bei den Reptilien zum grössten Teil hinten an der Peripherie, bei den Vögeln durch das ganze Organ verteilt, bei den Säugern endlich in seinem Innern gelegen ist.

Ferner behauptet Aichel, dass bei einem menschlichen Embryo von 3 Monaten sich der Bau des Markes dadurch charakterisiere, dass zahlreiche venöse Kapillaren, die von der Vena centralis ausgehen, die Zellstränge, aus denen das Mark sich zusammensetzt, trennen. Aichel will auch feststellen, dass die Tremung von Rinde und Mark in dem ursprünglich gleichartigem Gewebe dadurch bemerkbar wird, dass von der Kapsel ausziehende Bindegewebszüge die Randteile in einzelne Zellhaufen teilen. Später erst trateu nach Aichel in den mittleren Abschnitten Gefässe auf, die die Zellen der Anlage in Stränge sondern. Dieses geschieht zu einer Zeit, in der von einem Einwandern von Zellen des Sympathicus nicht mehr gesprochen werden kann. Aichel glaubt daher, dass die eingewanderten Nervenbestandteile aus dem Sympathicus lediglich dazu verwendet werden, die reichen Nervenbestandteile zu liefern, denen man in der Nebenniere des Erwachsenen begegnet, dass sich aber Mark und Rinde aus demselben Urgewebe entwickeln.

Eine Differenzierung in Mark und Rinde ist nach meinen obigen Ausführungen in dem von Aichel angefülsrten Stadium nicht vorbanden, da die Einwanderung in das Centrum und die Umbildung erst begann, vielleicht die Umbildung der eingewanderten Sympathicus - Bestandteile zu chromaffinen Zellen in dem $\mathrm{Aichel}$ schen Embryo überhaupt noch nicht anfing. Das aber, was Aichel als im mittleren Anteil gelegene, durch Gefässe in Stränge geteilte Zellmassen ansieht, muss ich nach meinen Befunden als Rindenzellen, speziell als Zona reticularis 
Beiträge zur Anatomie u. Entwickelung d. menschlichen Nebenniere. 511

deuten, deren Aussehen in jener Zeit, wo sie ganz im Centrum liegt, wohl leicht mit jener von Marksubstanz verwechselt werden kann.

Wir haben also nach meinen obigen Befunden gesehen, dass der als Marksubstanz bezeichnete Abschnitt der menschlichen Nebenniere sich einzig und allein aus dem Sympathicus in der. Weise entwickelt, dass zellige Elemente aus den Anlagen der abdominalen Plexusganglien in die epitheliale Substanz der Nebenniere einwandern und nach und nach centralwärts gelangen.

Die eingewanderten sympathischen Bildungszellen formen sich dann innerhalb der Nebenniere zu chromaffinen Zelleu um und zwar noch lange nach dern intrauterinen Leben. Es liegt eine Analogie vor mit den Befunden Zuckerkandls an den sympathischen Nebenkörpern, die sich in ganz ähnlicher Weise aus dem Sympathicus differenzieren, wie die Marksubstanz innerhalb der Nebenniere.

Wir haben infolgedessen die nervöse Substanz der Nebenniere weder für ein drüsiges, noch epitheliales Organ anzusehen, sondern für eine besondere Art von Sympathicus-Derivaten, den chromaffinen Zellen. Sie bilden - abgesehen von den spärlichen Ganglienzellen und Nervenfasern - die nervöse Substanz der Nebenniere.

Der Ansicht Aichels und der in jüngerer Zeit von $\mathrm{Haller}$ ausgesprochenen, dass sich die Suprarenalkörper der Selachier (also jener Organe, die der Marksubstanz der Nebenniere der höheren Säuger entsprechen sollen) aus den Querkanälchen der Uniere entwickeln sollen, kann ich derzeit noch nicht begegnen, doch hat Kohn - wie ich glaube, vollkommen einwandfrei nachgewiesen, dass auch die Suprarenalkörper der Selachier sich allein aus dem Sympathicus entwickeln. 
Ich möchte hier schliesslich noch einige Worte über die accessorischen Nebennieren sagen, deren Entstehung ich im Gegensatze zu Aichel ebenfalls nicht aus den Querkanälchen, (beim Weibe speziell aus denon des Epioophoron) ableite. Ich habe schon oben darauf hingewiesen, dass durch die Einwanderung des Sympathicus häufig Teile der Rindenanlage abgelöst werden und dann als freie Körper in den Plexus.Anlagen liegen bleiben, andererseits längs der Gefässe der Geschlechtsdrüsen samt diesen beckenwärts ziehen. Dafür spricht: dass accessorische Nebennieren des Plexus solaris sehr haufig sind; wir finden solche ohne Mark, welche zu einer Zeit entstehen, wo bloss sympathische Bildungszellen einwandern und kleine Rindenteile ablösen, zu diesen rechne ich auch jene,. die wir in der Nähe der Geschlechtsdrüse vorkommen und immer marklos sind, ebenso wie wir sie dem ganzen Verlaufe der Becken- und Bauchvenen entlang finden, also an Orten, wo gewiss keine Querkanäle der Uruiere vorkommen, z. B. an der Vena spermatica in der Nahe der fossa iliaca; in späterer Zeit ist es deukbar, dass solche Rindenteile, die an ihrer Peripherie sympathische Bestandteile enthalten, samt diesen durch einwandernden Sympathicus abgelöst werden; in dieser Weise lässt sich das Vorkommen accessorischer Nebennieren mit schmaler nervöser Schale erklären; diese Form findet sich deshalb nicht in tiefer kaudal gelegenen Körperpartien weil sie sich so spät entwickelt, dass von einem nach abwärts Wandern nicht mehr die Rede sein kann, zu einer Zeit nämlich, in der die Geschlechtsdrüsen samt den sie begleitenden Gefässen und bindegewebigen Bestandteilen bereits beckenwärts gewandert sind.

In ähnlicher Weise liessen sich die Bildungen erklären, bei welchen ein kleiner Rindenzipfel durch einen schmalen Hals mit der übrigen Nebenniere verbunden ist; hier ist die $\mathrm{Ab}$ schnürung nicht vollkommen gewesen. 
Ferner lässt sich mit dieser Auffassung sehr gut die Thatsache vereinen, dass accessorische Nebennieren stets an der medialen Seite des Hauptorganes, also dort, von wo das Eindringen von nervöser Substanz erfolgt, zu beobachten sind, niemals an der lateralen Seite. Die Häufigkeit accessorischer Neben nieren ist ebenfalls nicht sonderlich auffallend, weil eben die Einwanderung immer mit Zerklüftung der medialen Nebennierenteile verbunden ist. Aus diesen Gründen kann ich die Ansicht Aichels, die accessorischen Nebennieren entsprächen den Suprarenalkörpern nicht acceptieren, wozu noch kommt, dass die Suprarenalkörper aus chromaffinen Zellen bestehen, also Sympathicus-Derivate sind, während ja die accessorischen Nebennieren vor allem die an den Geschlechtsvenen, nur aus Rinde bestehen, also höchstens mit den Interrenalkörpern verglichen werden könnten.

\section{Histologische Beobachtungen.}

Zum Schlusse meiner Arbeit möchte ich noch einige Thatsachen zur Histologie der menschlichen Nebenniere anführen, obwohl auch diesem Gebiet, ebenso wie der Entwickelungsgeschichte des Organes eine sehr grosse Anzahl von Arbeiten gewidmet wurden. Ich habe nicht die Absicht, die Histologie der Nebenniere ausführlich zu besprechen, sondern will nur einige Punkte hervorheben, die noch Gegenstand von Kontroversen sind, andererseits einiges hervorheben, was noch überhaupt nicht - soweit ich die Litteratur kenne, beobachtet wurde. Die ganze grosse Anzahl von Arbeiten bier zu besprechen, würde zu weit führen, ich werde bei den einzelnen Abschnitten auf die Ansicht der verschiedenen Autoren zurückkommen. 


\section{Stroma der Nebenniere.}

Was zunächst die Technik der Darstellung des Nebennierenstromas betrifft, so wurden von den Autoren die verschiedensten Methoden angeführt. So verwendet $\mathrm{Flint}$, der in letzter Zeit seine Studien über das Reticulum der Nebenniere (speziell der des Hundes) veröffentlichte, nach Verdauung der frischen Schnitte in Pankreatin eine Färbung, die sich der von Giesson angegebenen anschliesst. Eine zweite ist die von Mall angegebene Färbung mit wässerigem Nigrosin, nach vorhergegangener Behandlung mit Pankreatin. Auch die Weigertsche Methode (Resorcin-Fuchsin), sowie Orcein kommen zur Verwendung, ebenso wie die Giessonsche Färbung, auch in ihrer von $\mathrm{Hansen}$ angegebenen Modifikation.

Die schönsten Resultate, ohne vorhergehende Verdauung mit Pankreatin, lieferte mir zur Darstellung des bindegewebigen Stromas die von Benda ${ }^{1}$ ) angegebene neue Färbungsmethode für Neuroglia. Benda giebt in dieser Abhandlung drei verschiedene Methoden zur Darstellung der Glia-Fasern an, von denen sich besonders die erste für Darstellung von Bindegewebe in Organen, die nicht Centralnervensystem sein müssen, in vorzüglichster Weise eignet. Es ist das die Färbung, bei welcher die Objekte nach vorhergegangener Behandlung mit Weigertscher Gliabeize im Stück und Nachbeizung in Liquor ferri sulfurici im Schnitte mit sulfalizarinsaurem Natron und nachher mit Toluidinblau gefärbt werden. Diese Methode, auf deren genaue Wiedergabe ich verzichte, ist trotz aller Kompliziertheit eine sehr sichere und liefert Resultate, die selbst die feinsten Bindegewebsfäserchen erkennen lässt, wie sie durch die Giessonsche Methode nicht mehr dargestellt werden können. Dazu

1) Benda, C., Erfahrungen über Neurogliafärbung und eine neue Fälbungsmethode (Neurol. Centralblatt Bd. 19, 1900. Nr. 17. 
kommt noch die grosse Haltbarkeit der Präparate, welche der Giessonschen Methode leider sehr stark mangelt. An nach Benda (Färbung A) behandelten Präparaten sind Kerne und Plasma lichtblau (Toluidinblau), das Bindegewebe durch das sulfalizarinsaure Natron stark braungelb tingiert. Es zeigt sich dann folgeudes Bild: Von dem Bindegewebe der Kapsel ragen kurze Fortsätze in das Innere des Organes, die sich untereinander zu einem ziemlich grobmaschigen Netzwerk verflechten, in denen die Zellen der Zona glomerulosa eingelagert sind. Dieses Netzwerk sendet aber beim Menschen (so wie nach Flint beim Hund) nicht lange Bindegewebsstreifen ins Innere, welche die Anordnung der Zona fasciculata bedingen, sondern es folgt auf die grobmaschige Zone eine solche mit engeren Maschen, in welchen die Zellen der Zona fasciculata liegen: erst von diesen Maschen reichen dann Fortsătze ins Innere, welche langgestreckt verlaufend ungefähr durch ein Drittel des ganzen Organes zu verfolgen sind.

Dort verschmelzen die Fasern wieder zu einem sehr weitmaschigen Netzwerk, die die Zona reticularis bilden. Das Bindegewebe des Markes wird durch ein grobmaschiges Reticulum repräsentiert, in welchem die Zellen äusserst dicht liegen und zwar zu mehreren vereint, immer von einer ziemlich dicken bindegewebigen Hülle umgeben, aber nicht frei zwischen den Maschen des Reticulum; das Stroma verhält sich ebenso wie das der Zuckerkandlschen Organe. Die zwischen den Zellgruppen verlaufenden Bindegewebsstreifen von grösserer Breite führen die Gefässe, während die Ganglienzellen nicht frei zwischen den chromaffinen Zellen lagern, sondern im Nerven eingelagert sind, wie dies auch Ebner - Koelliker auf Fig. 1132 des „Handbuches der Gewebelehre" abbildet. Die elastischen Fasern verhalten sich so, wie sie von anderen Autoren beschrieben wurden. 


\section{Rindenzellen.}

Genau auf die Verhältnisse der histologischen Struktur der Rindenzellen einzugehen, halte ich für überflüssig, da den vielen einschlägigen Arbeiten (in letzter Zeit besonders Hultgren und Andersson) wenig hinzuzufügen bleibt. Ich will mich bloss darauf beschränken, einige Angaben zu besprechen, die in jüngster Zeit Guieysse in seiner Arbeit über die Nebenniere machte und einige neue Beobachtungen hinzufügen.

Guieysse teilt die Zona fasciculata in zwei Zonen ein eine "couche spongieuse" oder partie externe und eine innere couche fasciculée (partie interne).

Von den Zellen der conche spongieuse sagt Guieysse folgendes: „La caractéristique de ces cellules est la structure spongieuse de leur protoplasma. Elles représentent le schéma de ce que Buetschli a appelé la structure alvéolaire.

Je ne pourrais mieux comparer ce protoplasma quà un mousse très légère, à du blanc d'oeuf très battu. Le corps cellulaire de ces cellules est formé par de fines trabécules de protoplasma, renfermant un liquide."

Guieysse nennt diese Zellen Spongiocyten. Mit Recht hebt Guieysse hervor, dass diese Zellen typisch in jeder Nebenniere vorkommen und zwar als mehr minder breite äussere Zone der fascikulären Schichte. Auch beim Menschen finden wir sie in Nebennieren von älteren Individuen, niemals aber beim Neugeborenen und Embryo. Das Protoplasma dieser Zəllen bleibt immer farblos, bloss durch spezifische Fettfärhungen (Sudan) lässt sich nachweisen, dass die Spongiocyten Guieysses bloss verfettete Rindenzellen darstellen, bei denen nach Behandlung mit Alkohol oder Äther das Fett gelöst wird und nur die Grenzen der Fettzellen zurückbleiben. Wir finden diesen Verfettungsvorgang vorzüglich in der an die Wachstumszone (Zona glomerulosa), direkt angrenzenden Partie der Zona fasciculata. 
Es wäre demnach die „couche spongieuse“ als verfettete Rindenzone anzusprechen.

Auffällige Färbungen, welche auf einen besonderen physiologischen Zustand deuten, fand ich in der mehr gegen die Mitte zu gelegenen Partie der Zona fasciculata und reticularis. Von den Verschiedenheiten der Körnungen nach Behandlung mit Haidenheins Eisenhämatoxylin will ich nicht sprechen, weil es mir nicht gelungen ist, so weit gehende Uuterschiede, wie sie beispielsweise Hultgren und Andersson beschrieben, zu finden. Dagegen zeigten sich auffällige Thatsachen nach $B$ handlung mit polychromem Methylenblau und Färbung mit Muchämatein und Thionin.

Unna hat (Monatshefte für praktische Dermatologie 1895, Bd. 20) eine Methode angegeben - allerdings für die Haut nach welcher es gelingt, „saure" Kerne rot und "basische" „blau“ zu färben: es ist dies die Färbung mit polychromem Methylenblau und Differenzierung in 33\% Tanninlösung. An derartig gefärbten Schnitten durch die Nebenniere findet man folgendes Bild. Die Zona glomerulosa zeigt durchwegs blaues Plasma und blaue Kerne. Das verfettete Protoplasma der äusseren Fasciculata-Schichte färbt sich überhaupt nicht; die innere Schichte der Zona fasciculata und reticularis zeigen aber, dass neben Zellen mit tief dunkelblauem Plasma und blauem Kern, solche liegen, die ein hellblaues Plasma und deutlich roten Kern besitzen; diese auf den Farbstoff so verschieden reagierenden Zellen liegen regellos nebeneinander und unterscheiden sich auch durch ihre Grösse (Abb. 9). Die blauen Zellen sind kleiner als die mit rotem Kern versehenen. Denselben Farbunterschied bekommt man am frischgefärbten Strichpräparat.

Es zeigt sich ferner, dass viele der blau gefärbten Zellen sich auch mit Schleimfarben distinkt färben; und zwar zeigt es sich, dass die sich mit Schleimfarben färbenden Zellen eine gauz eigentümliche Gruppierung annehmen, indem sie, dreieckig 
bis halbmondförmig um andere rundliche Zellen liegen, die keive derartige Reaktion geben. Solche Zellen finden sich weder im Mark noch in der Zona glomerulosa (Abb. 10). - Es scheint demnach, dass die Zellen der Nebenniere ein saures und ein basisches Sekret liefern oder dass diese eine Thatsache nur einen besonderen physiologischen Zustand einer und derselben Zellform repräsentiert. Erwähnt sei noch, dass die basischen Zellen diejenigen sind, die sich nach $\mathrm{Haidenhein} \mathrm{besonders}$ stark tingieren.

An den Markzellen, also den chromaffinen Elementen, konnte ich derartige Zeichen einer inneren Sekretion nicht nachweisen. 


\section{Litteraturverzeichnis.}

1. Aichel, O.tto, Vergleichende Entwickelungsgeschichte und Stanmesgeschichte der Nebenniere. Archiv f. mikrosk. Anatomie u. Entwickelungsgeschichte Bd. 56. Heft I. 1900.

2. Alexander, Karl, Untersuchungen über die Nebennieren und ihre Beziehungen zum Nervensystem. Beiträge zur pathologischen Anatomie und zur allgemeinen Pathologie von Ziegler Bd. 11. 1892.

3. A rnold, Julius, Ein Beitrag zur feineren Struktur und dem Chemismus der Nebenniere. Archiv f. pathol. Anatomie von Virchow Bd. 35.1866.

4. Balfour, F. M., Monograph on the developpement of Elasmobranch Fishes. London 1870.

5. -- Über den Bau und Entwickelung der Suprarenalkörper. Biolog. Centralblatt 1881. Nr. I.

6. Bergmann, C., Dissertatio de glandulis suprarenalibus (Göttingen 1839).

7. Braun, Über den Bau und Entwickelung der Nebennieren bei Reptilien. Arbeiten aus dem zoologisch-zootomischen Institut der Universität Würzburg. Bd. V. 1882.

8. Brunn, A. v., Ein Beitrag zur Kenntnis des feineren Baues und der Entwickelung der Nebennieren. Archiv f. mikr. Anatomie. Bd. VIII. 1872.

9. Canalis, P., Contribution à l'étude du developpement et de la pathologie des capsules surrénales. Internationale Monatsschrift für Anatomie und Physiologie. Bd. IV.

10. Dostoiewsky, Ein Beitrag zur mikroskopischen Anatomie der Nebennieren der Säugetiere. Archiv f. mikrosk. Anatomie. Bd. 27. 1886.

11. Dogiel, Die Nervenendigungen in den Nebennieren der Saugetiere. Arch. f. Anatomie u. Entwicklungsgeschichte. 1894.

12. Eberth, C. J., Die „Nebennieren" in Strickers Handbuch über Gewebelehre. 1871.

13. Ecker, A., Der feinere Bau der Nebennieren beim Menschen und den vier Wirbeltierklassen. Braunschweig 1846.

14. Frey, H., On the suprarenal capsules. Todd, Lyelopdaeia of Anatomy and Physiology, London 1849. 
15. Flint, Reticulum of the adrenal. Anat. Anzeiger. Bd. 16. 1899.

16. Fus ari, De la termin. d. fibr. nerv. d. l. capsules surrénales. Arch. ital. de biologie. Bd. 16.

17. Gottschau, M., Über Nebennieren der Säugetiere, speziell über die des Menschen. Sitzungsberichte der Würzburger phys. med. Gesellschaft. 1882.

18. - Über die Nebennieren der Säugetiere. Biol. Centralblatt. Bd. III. 1883. $\mathrm{Nr} .18$.

19. - Struktur und embryonale Entwickelung der Nebennieren bei Säugetieren. Archiv f. Anat. u. Physiologie. Mat. Abt. 1883.

20. Guiyesse, A., La capsule surrénale du cobaye. Histologie et Fonctionnement. Journal de l'anatomie et de la physiologie, trente-septième année 1901.

21. Harley, G., The histology of the suprarenal capsules in Lancet 5 . and 12. June 1858).

22. Henle, Zeitschrift f. rationelle Medizin Bd. 24. u. systematische Anatomie Bd. II. Heft 3.

23. Holm, F., Sitzungsberichte der k. Akademie der Wissenschaften in Wien Bd. 53. 1866.

24. Hultgren und Andersson, Studien über die Physiologie und Anatomie der Nebennieren. Skandinavisches Archiv f. Physiologie Bd. 19 H, 2-5.

25. Huschke, Lehre von den Eingeweiden und Sinnesorganen des menschlichen Körpers von S. v. Soemmering. Leipzig 1844.

26. In aba, M., Notes on the developpement of the suprarenal bodies in the. monse. Journal of the college of science. Tokio, Vol. IV. S. 1.

27. Janošik, Bemerkungen über die Entwickelung der Nebenniere. Archiv f. mikrosk. Anat. Bd. 12, 1883.

28. - Bemerkungen über die Entwickelung des Genitalsgehäuses. Sitzungsbericht d. Kais. Akad. der Wissensch. in Wien. Bd. 90. H. 3. 1890.

29. Koelliker-Ebner, Handbuch der Gewebelehre. 6. Aufl. Bd. 3.

30. Kohn, Über die Nebenniere. Prager med. Wochenschr. Jahrgang 23. Nr. 17. 1898.

31. - Die Nebenniere der Selachier nebst Beiträgen zur Kenntnis der Morphologie der Wirbeltiernebenniere im Allgemeinen. Arch. f. mikrosk. Anat. 1898, Bd. 53.

32. - Die chromaffinen Zellen des Sympathicus. Anat. Anz. Bd. 15. 1899.

33. - Die Epitbelkörperchen. Ergebnisse der Anatomie und Entwickelungsgeschichte Bd. IX. 1899.

34. Kose, W., Über das Vorkommen " chromaffiner Zellen“ im Sympathicus des Menschen und der Säugetiere. Sitzungsber. d. Deutschen naturw.-med. Vereins f. Böhmen. "Lotos“ 1898. Nr. 6.

35. Krause, Lebrbuch d. mikrosk. Anatomie 1879.

36. Leydig, Beitrag zur mikrosk. Anatomie u. Entwickelungsgeschichte der Rochen u. Haie. Leipzig 1852.

37. Lubarsch, Ergebnisse der spez. pathol. Morphologie und Physiologie der Nebennieren. Lubarsch u. Ostertag. Wiesbaden 1856.

38. Meckel, Abhandlung aus der menschl. und vergl. Anatomie und Physiologie. Halle 1806. 
39. Mitsukuri, On the developpement of the suprarcnal bodies in Mammalia Quarterly journal of mikrosk. Science Vol. XXII.

40. Moers, Ứber den feineren Bau der Nebenniere. Archiv für pathologische Anatomie Bd. 29.

41. Mühlma nn, Zur Histologie der Nebenniere. Virch. Arch. Bd. 146.

42. Nage l, Über die Struktur der Nebennieren. Müllers Arcbiv für Anat. u. Physiologie 1834.

43. Onody, Entwickelung des Sympathicus. Archiv für mikroskop. Anat. Bd. XXVI. 1888.

44. Pfaundler, Zur Anatomie der Nebenniere. Sitzungsber. der Kaiserl. Akad. d. Wissenschaften in Wien. Bd. 101. 1892.

45. Rabl, Hans, Entwickelung der Nobenniere bei den Vögeln. Arch. für mikrosk. Mat. Bd. 38. 1891.

46. Schmidt, Dissertatio de gland. suprarenalibus. Trag. ad Viàdr. 1785.

47. Semon, Studien über den Bauplan des Urogenitalsystemes der Wirbeltiere. Jena 1891.

48. Stannius, Nouveau manuel d'anatomie comparée. T. I.

49. Stilling, Zur Anatomie der Nebennieren. Virchows Arch. Bd. 109. 1887.

50. Valenti, Sullo sviluppo delle capsule surrenale nel pollo ed in accuni mammiferi. Pisa 1889.

51. Vincent, $\mathrm{S}$ wale, The comparative Histology of the suprarenal capsules Intern. Monatsehrift f. Anat. u. Physiolog. Bd. 15. 1898.

52. Weldou, On the suprarenal Bodies of Vertebrata. Quart. Journ. of Mikroscop. Sc. Vol. 25. 1885.

53. W i es el, J., Über accessorische Nebennieren am Nebenhoden des Menschen. Sitzungsber. der Akademie der Wissenschaften in Wien. Bd. 108.

54. Wi esel, Über die Entwickelung der Nebenniere des Schweines, besonders der Marksubstanz. Dieses Archiv. Heft 50, 1900.

55. Z u ckerkandl, E., Über Nebenorgane des Sympathicus im Retroperitonealraum des Menschen. Verhandlungen der anat. Gesellschaft auf der 15. Vers, in Bonn 1901. S. 96. 


\section{Figurenerklärung.}

Figur 1. Schnitt durch die Nebennierenanlage eines $12^{1 / 2} \mathrm{~mm}$ langen menschlichen Embryo in der Höhe des Abganges der oberen Gekrösarterie. Vergr. $85: 1$

A Aorta. S Sympathicus. R Rindenanlage der Nebenniere.

Figur 2. Schnitt durch die Nebennierenanlage eines $17 \mathrm{~mm}$ menschlichen Embryo in gleicher Höhe wie oben. Vergr. $85: 1$

A Aorta. S B sympathische Bildungszellen. R Rindenanlage.

Figur 3. Aus der Nebennierenanlage eines $95 \mathrm{~mm}$ menschlichen Embryo die gezeichnete Stelle liegt in der Zona fasciculata. Vergr. 170:1

S B sympathische Bildungszellen. chr. Z chromaffine Zellen. R Rindenzellen.

Figur 4. Schnitt durch die Nebenniere eines neugeborenen Kindes; die gezeichnete Stelle liegt nicht central im Organe. Vergr. 150:1

R Rinde. chr. Z chromaffine Zellen.

Figur 5. Aus der Marksubstanz eines einjährigen Kindes. Behandlung für Chromreaktion, Färbung mit Toluidinblau und Säurefuchsin. Vergr. 170:1. (Die gelb grfärbten Zellen haben im Präparate einen grünlichen Ton.)

B Bindegewebe. chr. Z chromaffine Zellen.

Figur 6. Aus der Marksubstanz eines vierjährigen Kindes. Behandlung nach Benda. Vergr. 270:1

B Bindegewebe. M Markzellen (chromaffine Zellen).

Figur 7. Aus der Nebenniere eines siebenjährigen Kindes. Die gezeichnete Stelle stammt aus der Zona fasciculata

R Rinde. R f Fasciculata Zellen ("Spongiocyten" nach Guiyesse). s B sym-

pathische Bildungszellen. vhr. Z chromaffine Zellen. Vergr. 200:1

Figur 8. Aus der Nebenniere eines vierjährigen Kindes. Vergr. 85:1 R Rinde. M Mark. Z g Zona glomerulosa.

Figur 9. Aus der Nebenniere eines Erwachsenen. Färbung nach Unna mit polychromem Methylenblau. Vergr. 170:1

bas $\mathrm{K}$ basische Kerne. s $\mathrm{K}$ saure Kerne.

Figur 10. Aus der Nebenniere eines Erwachsenen. Färbung mit Muchämatein. Vergr. $200: 1$

Z m M Rindenzelle mit Mucinreaction (Zona fasciculata). R Rindenzelle. 